\title{
A IMPORTÂNCIA DAS AULAS PRÁTICAS PARA O ENSINO DE JOVENS E ADULTOS: UMA EXPERIÊNCIA DE PARTICIPAÇÃO NO PROGRAMA RESIDÊNCIA PEDAGÓGICA
}

The importance of practical classes for Youth and Adult Teaching: an experience of participation in the Pedagogical Residency Program

La importancia de las clases prácticas para la educación de jóvenes y adultos: una experiencia de participación en el Programa de Residencia Pedagógica

João Victor Soares da Silva Rodrigues ${ }^{1}$, Taluany Silva do Nascimento ${ }^{2}$, Luziane Miranda da Silva ${ }^{3}$, Kleiton Dias Meireles ${ }^{4}$, Etiene Fabbrin Pires Oliveira ${ }^{5}$, Carla Simone Seibert ${ }^{5}$ *

${ }^{1}$ Graduando do Curso de Ciências Biológicas Licenciatura, Universidade Federal do Tocantins (UFT), campus Porto Nacional, Brasil

${ }^{2}$ Pós-graduanda no PPG Biodiversidade, Ecologia e Conservação, Universidade Federal do Tocantins (UFT), campus Porto Nacional, Brasil

${ }^{3}$ Professora da Rede Municipal de Ensino do Município de Porto Nacional, Tocantins, Brasil

${ }^{4}$ Professor da Rede Estadual de Ensino, Porto Nacional, Tocantins, Brasil

${ }^{5}$ Curso de Ciências Biológicas, Universidade Federal do Tocantins (UFT), campus Porto Nacional, Brasil

*Correspondência: Curso de Ciências Biológicas, Campus de Porto Nacional, Rua 3, S/N, Lote 17, Jardim dos Ipês, Porto Nacional, Tocantins, Brasil.CEP:77.500-000.e-mail seibertcs@uft.edu.br.

Artigo recebido em 19/02/2020 aprovado em 09/04/2020 publicado em 17/04/2020.

\section{INTRODUÇÃO}

A Educação de Jovens e Adultos (EJA) é uma modalidade dentro do Ensino da Educação Básica, que atende um público bastante heterogêneo, cuja faixa etária não se encaixa dentro do ensino regular (GONÇALVES et al., 2012).

No ensino de ciências é importante promover ao aluno jovem e adulto o contato, sempre que possível, com os fenômenos vistos de forma teórica em sala, para que o educando possa interagir e construir uma ideia fiel dos conteúdos (LEITE et al., 2005). Portanto, o professor deve buscar ações que respondam as necessidades de cada aluno, apresentando os conteúdos de forma objetiva e dinâmica para facilitar a compreensão. Assim, as aulas práticas entram com o papel de despertar a curiosidade e chamar a atenção dos alunos (BORGES, 2002). Contudo, esse tipo de aula depende da didática do DOI: http://dx.doi.org/10.20873/uftsupl2020-8487 professor, sendo necessário que essas metodologias sejam trabalhadas em sua formação, bem como, a adequação da teoria e prática para os diferentes níveis de ensino (TELES et al., 2016).

$\mathrm{O}$ aperfeiçoamento de metodologias e o desenvolvimento da didática foram fatores trabalhados durante o Programa Residência Pedagógica, que por ser uma espécie de estágio, estreitou os laços entre a comunidade escolar e a universidade. Esse resumo tem como objetivo apresentar a experiência vivida no programa Residência Pedagógica a partir de uma aula dinâmica realizada nos laboratórios da Universidade Federal do Tocantins (UFT), campus Porto Nacional, para os alunos do EJA.

\section{METODOLOGIAS E MATERIAIS}


Para exemplificar a experiência de regência, desenvolvida no Programa Residência Pedagógica, apresenta-se aqui o relato de uma atividade prática, relizada com uma turma do $6^{\circ}$ e $7^{\circ}$ ano/EJA, da Escola Municipal Celso Alves Mourão, no segundo semestre de 2019. A atividade prática consistiu em levar essa turma ao Campus da Universidade Federal do Tocantins de Porto Nacional (UFT), para fazer a observação e manuseio de diferentes materiais didáticos pertencentes aos laboratórios de ensino do Curso de Ciências Biológicas.

A atividade foi realizada após aula teórica sobre "Os cinco reinos". Para conduzir a atividade prática foi elaborado um roteiro para registro do nome, reino, grupo e principais características dos exemplares disponibilizados pelos laboratórios. A atividade contemplou quatro laboratórios: Microscopia, Herbário, Anatomia Animal Comparada e Paleobiologia. Os alunos foram divididos em quatro grupos de cinco integrantes, para facilitar o acesso aos espaços e a dinâmica das atividades.

No Laboratório de Paleobiologia os alunos tiveram uma introdução sobre a área de pesquisa e após, o contato com fósseis de animais e vegetais. Cada aluno recebeu um fóssil, fez a identificação e classificação do material. No Laboratório de Microscopia os alunos identificaram animais do Reino Metazoa: Moluscos, Anelídeos, Artrópodes e Equinodermos. Além da identificação do nome, grupo e característica do animal os alunos fizeram um esquema, com base no material observado em lupa. No Laboratório de Anatomia Animal Comparada foram trabalhados os grupos de vertebrados: Peixes, Anfíbios, Répteis, Aves e Mamíferos. No Herbário foi abordado o Reino Metaphyta, no entanto, a atividade iniciou com a exposição dos procedimentos para preparo e conservação das plantas armazenadas no acervo (exsicatas), posteriormente cada aluno recebeu um exemplar para estudo. Retornando à escola foi realizada uma roda de conversa para que os alunos pudessem expor suas impressões sobre a aula prática, sendo avaliado também a metodologia utilizada.

\section{RESULTADOS E DISCUSSÃO}

Durante a prática foi possível perceber maior interação dos alunos com o professor, despertando curiosidade com relação aos materiais expostos e ao conteúdo. Por vezes, as perguntas também estavam relacionadas à universidade e aos cursos ofertados no campus. De volta à escola, os alunos avaliaram de forma positiva a experiência e após a correção dos roteiros a metodologia provou sua eficácia, através do bom desempenho dos alunos. Esse fato corrobora com a afirmação de Leite et al. (2005), quando afirma que no ensino de ciências o profissional deverá relacionar os fenômenos biológicos, químicos e físicos com as vivências desses alunos, instigando uma percepção crítica da sua relação com os demais seres vivos e como suas ações transformam o meio.

\section{CONCLUSÃO}

A prática para o ensino no EJA foi de grande valia, pois os alunos deram um feedback positivo, demonstrando que foi mais produtivo ver e tocar em organismos que não são de seu cotidiano, associando assim com o conteúdo. Foi possível perceber maior participação e interesse dos alunos, diferente do que ocorre em sala de aula. Essa abordagem vivencial cria lembranças e traz um aprendizado que os alunos levam para vida toda.

Também foi possível proporcionar aos alunos do EJA um contato com a Universidade pública, a maioria relatou que nunca havia conhecido o campus. Assim, fez com que a distância entre a comunidade e a universidade diminuísse, incitando-os a sonhar com a formação superior.

Por fim, conclui-se que essa oportunidade foi possível graças ao programa Residência Pedagógica, 
que proporcionou aos Residentes uma experiência repleta de desafios e aprendizado, contribuindo com a formação profissional.

Todos os autores declararam não haver qualquer potencial conflito de interesses referente a este artigo.

\section{REFERÊNCIAS}

BORGES, Antônio Tarciso. Novos rumos para o laboratório escolar de ciências. Caderno Brasileiro de Ensino de Física, v. 19, n. 3, p. 291-313, 2002.
GONÇALVES, Á. K. PEREIRA, C.A MOURA, R.C.G. Relação entre a teoria e a prática da Educação Ambiental na EJA do SESC-Petrolina/PE. Revista de Educação, Ciências e Matemática, v. 2, n. 1, 2012.

LEITE, A. C. S.; SILVA, P. A. B.; VAZ, A. C. R. A importância das aulas práticas para alunos jovens e adultos: uma abordagem investigativa sobre a percepção dos alunos do PROEF II. Ensaio pesquisa em educação em ciências (belo horizonte), v. 7, n. 3, p. 166-181, 2005.

TELES, D. A.; SOARES, M. P. S. B.. Educação de jovens e adultos: desafios e possibilidades na alfabetização. Revista Educação e Emancipação, p. 80-102, 2016 